\title{
HORTICULTURAL PROTOCOLS TO AID THE CONSERVATION OF MELAMPYRUM SYLVATICUM, OROBANCHACEAE (SMALL COW-WHEAT), AN ENDANGERED HEMIPARASITIC PLANT
}

\author{
Rhiannon J. Crichton ${ }^{1}$, Sarah E. Dalrymple ${ }^{2}$ \& Peter M. Hollingsworth ${ }^{3}$
}

\begin{abstract}
A BSTRACT
Small cow-wheat is an annual, hemiparasitic plant that is endangered in the UK. Attempts at restoration have been hampered by a lack of species-specific horticultural knowledge. This paper outlines the methods used to collect, store and germinate small cow-wheat seed, and to cultivate the plant at the Royal Botanic Garden Edinburgh. The germination rates achieved using two different approaches are reported and the factors potentially influencing germination and establishment success are discussed.
\end{abstract}

\section{INTRODUCTION}

Melampyrum sylvaticum, L. (small cow-wheat) is a generalist hemiparasitic, summer annual that grows as an understory herb in open deciduous and coniferous woodlands, distributed across temperate European mountain ranges and across the Scandinavian and Russia boreal zone (Soó \& Webb, 1972; Dalrymple, 2007). The species is native to the UK. It was once widely distributed across upland areas but is now known from only 19 isolated populations, all located in Scotland. Only three of the extant populations are relatively large and stable. These have census sizes of 1,500-8,000 plants and cover areas of $30-65 \mathrm{~m}^{2}$. The remaining 16 populations contain fewer than 300 plants and cover correspondingly small areas. On the basis of no plants being recorded at a site for more than two consecutive years, two Scottish populations have become extinct since 2004 (Dalrymple, 2007) with a number of other small populations not being monitored. Between 2005 and 2009 all four remaining Northern Irish populations disappeared, making the species now extinct in that country (Maeve Rafferty, Ulster Wildlife Trust, pers. comm.).

Because of this relatively recent and rapid decline in population abundance, small cow-wheat is IUCN Red-Listed as 'endangered' in the UK (Cheffings \& Farrell, 2005) and designated by the UK government as a Biodiversity Action Plan species (UK Biodiversity Group, 1999). The causes of population decline are believed to be a

\footnotetext{
1. Rhiannon J. Crichton is a PhD student at the Royal Botanic Garden Edinburgh and the Institute of Biological and Environmental Sciences, University of Aberdeen.

Address: 20A Inverleith Row, Edinburgh, EH3 5LR.

Email: Rhiannon.Crichton@gmail.com

2. Sarah E. Dalrymple is Conservation Ecologist at the Centre for Evidence-Based Conservation in Bangor, Wales.

Email: S.E.Dalrymple@gmail.com

3. Peter M. Hollingsworth is Director of Science at the Royal Botanic Garden Edinburgh.

Email: P.Hollingsworth@rbge.ac.uk
} 
combination of habitat loss and degradation over long time scales (Rich et al., 1998; Dalrymple, 2007), a lack of dispersal ability (Dalrymple, 2006), gradual climate change and over-collecting (Tennant, 2008).

Given the pervasive nature of the threats to the wild populations, and their continued loss, management interventions are necessary to safeguard the future of small cow-wheat in the UK. Translocations have been attempted with small cow-wheat through the Species Recovery Project (Dalrymple \& Broome, 2010). This was initiated in 2005 to fulfil Target 2 of the M. sylvaticum Species Action Plan (outlined within Dalrymple, 2006). This is "to establish, by 2010 , small cow-wheat at five suitable sites in order to commence the process of extending its distribution in Britain". Seed from three 'donor' populations was sown in six new sites over three years (between eighty-nine and five hundred seeds in any single translocation event in 2005, 2006 and 2008). The number of surviving plants at the most recent survey of the six sites (April or July 2009) ranged from zero to forty-two, equivalent to an average accumulated survival rate of 5.71 per cent (ranging between 0 and 28 per cent). These low rates of seed germination and plant survival were thought to be caused by unusually dry weather conditions, too great a dissimilarity in the ecological and environmental conditions of the new sites compared to the site the seed came from and/or dormancy-induced seed mortality (Dalrymple \& Broome, 2010). However, a general limitation in the design of restoration projects for this species is uncertainty as to the best horticultural methods to use.

As part of a wider research project studying the biology of small cow-wheat, protocols for seed collection, storage and germination were developed and two methods of growing this species were undertaken. To support future efforts in the restoration of small cow-wheat, we document the horticultural protocols used and the outcomes of these informal cultivation trials in this paper.

\section{BACKGROUND ON THE LIFECYCLE OF SMALL COW-WHEAT}

The biology of small cow-wheat is described here in brief; a detailed account can be found in the Biological Flora account for this species (Dalrymple, 2007).

Small cow-wheat is a hemiparasite, meaning that it parasitises water, nutrients and organic compounds from a 'host' plant whilst also making its own organic compounds by photosynthesis (Musselman \& Press, 1995; Těšitel et al., 2010a). In common with many other hemiparasites, it undergoes a 'double-germination' (Masselink, 1980). The first germination occurs in autumn/winter (October-January), after a sufficient period of cold temperatures, with the emergence of the radicle. The radicle will attach into the xylem vessels of the roots of other plants and over-winter in this state. The second germination occurs in spring (usually March), probably in response to warmer temperatures, with the emergence of the cotyledon leaves and plant growth.

The plant grows from a single erect stem which develops bilaterally symmetrical (left and right) nodes from which either a branch, or a bract and a flower, will grow (Fig. 1a). During the growing season the plant keeps its stomata open, irrespective of 


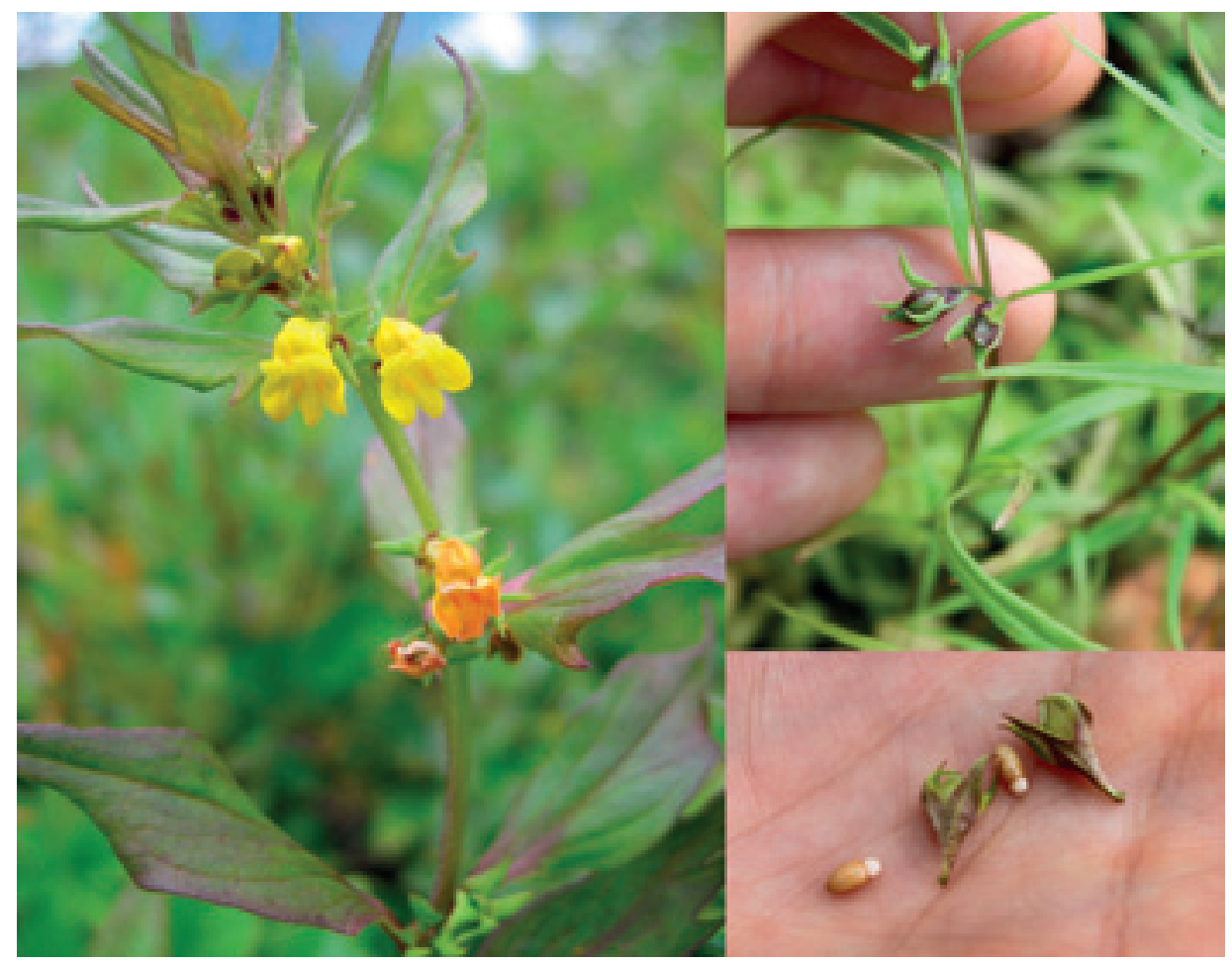

Fig. 1 (a) Growth form and flowers of small cow-wheat, (b) Seed-pod of small cow-wheat, pointing straight out, (c) Mature seeds dehisced out of their pods; note the creamy, pale-brown colour of the seed coat and the bright white elaiosome attached to the end of the seeds. Photos: Rhiannon Crichton.

conditions at the site that influence the rate of evapotranspiration, in order to draw water and nutrients from the host roots into its own leaves (Press et al., 1988). This feature is probably the key reason why the species has such strict requirements for cool, humid sites. For instance, in the UK, all of its sites are located besides running water or a large lake, are north-facing and/or are under tree cover (Dalrymple, 2006).

Small cow-wheat was thought to be predominantly out-crossing because it has small, golden-yellow, asymmetric flowers that are known to be attractive to insects, especially bees (Rumsey, 1994) (Fig. 1a). However, experiments have shown that the species is capable of seed-set in the absence of pollinators (Molau, 1993; Dalrymple, 2006), and preliminary genetic analyses suggest that self-pollination occurs with high frequency (Crichton et al., 2012).

Up to four seeds are produced per seed-pod (Fig. 1b) and dehisced from mid-summer (usually July) until plant death at the end of summer (usually August). Melampyrum ssp. seeds are the largest within the Orobanchaceae (Těšitel et al., 2010b) and seeds bear a lipid- and starch-rich elaiosome that is attractive to ants and therefore encourages active seed dispersal (Weiss, 1908) (Fig. 1c). The large seeds contain energy reserves to fuel 


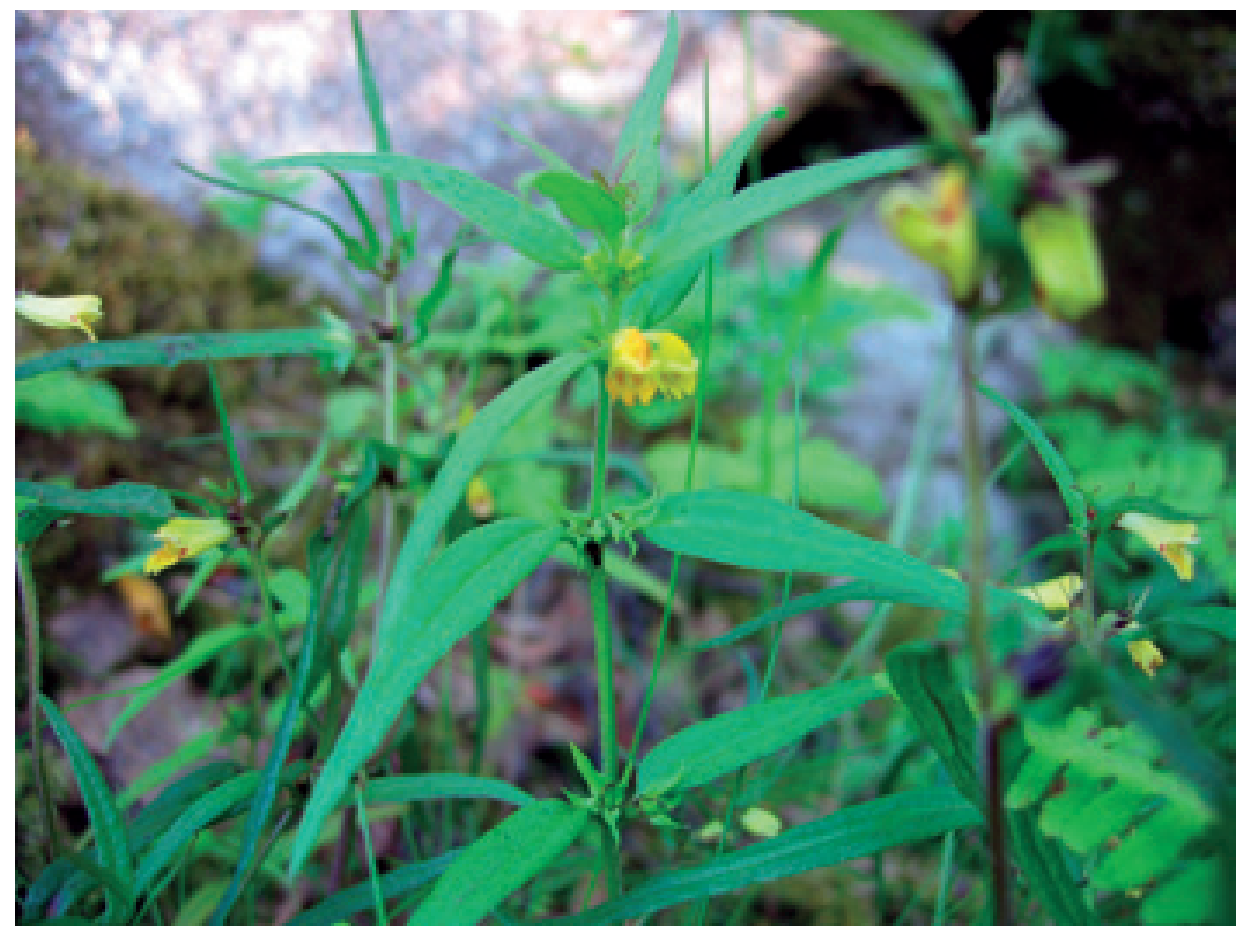

Fig. 2 The closely related species, small cow-wheat and common cow-wheat, growing together. Small cowwheat is in the foreground and distinguishable by the small, bright yellow corollas. Common cow-wheat is in the background and distinguishable by the paler, longer, narrower corollas. Photo: Rhiannon Crichton.

seed survival and radicle growth before attachment to a host. A limited seed bank has been observed in cultivation conditions, with plants germinating from seed that had been dormant for two over-wintering seasons (Alice Broome, Forest Research, pers. comm.).

Small cow-wheat is commonly confused with common cow-wheat (M. pratense L., Orobanchaceae) (Rich et al., 1998). Distinguishing features of small cow-wheat are the small, golden-yellow, open corolla (though white variants have been recorded in continental Europe, Těšitel et al., 2009), with a recurved bottom lip, and round seed pods that point straight out (Fig. 1a). Common cow-wheat, by contrast, has a longer, narrower corolla of variable colour (Fig. 2), with white, yellow and pink variants reported in the UK (Heather McHaffie, Royal Botanic Garden Edinburgh, pers. comm., Figs 3a \& 3b), and the seed pods are highly curved with the tip pointing downwards. 


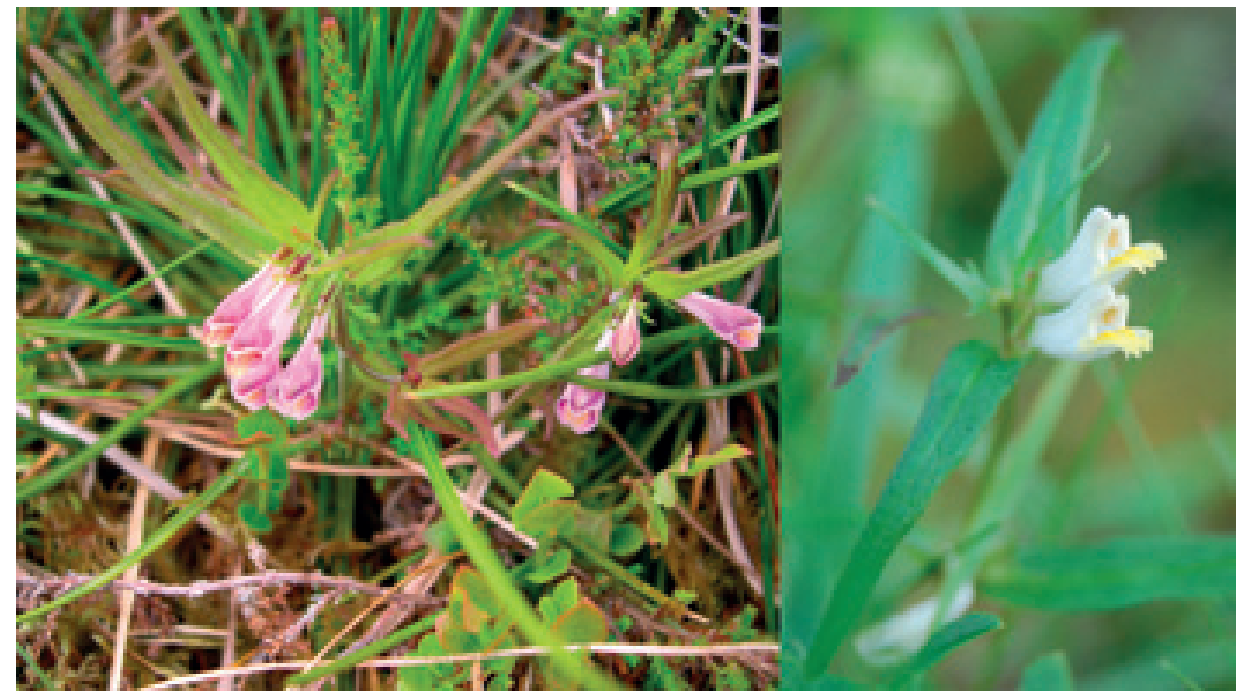

Fig. 3 (a) A pink corolla colour variant of the closely related species, common cow-wheat. Photo: Heather McHaffie. (b) A white corolla colour variant of the closely related species, common cow-wheat. Photo: Chris Horsfall.

\section{HORTICULTURAL OBSERVATIONS AND PROTOCOLS USED}

\section{Seed collection}

Seed was collected from two major sources. The first was a series of collections from wild populations in Scotland ('UK'), Sweden and Norway ('Scandinavia', or 'SC') in late July to early August (Table 1).

Seeds were collected by picking either whole seed-pods or the whole stem of the plant (containing many seed-pods) and putting them into zip-lock polythene bags containing moist moss and/or soil collected at the site.

The second major source of seeds came from a cultivation experiment set up by Sarah Dalrymple at the Cruickshank Botanic Garden, Aberdeen University, in 2007. In

\begin{tabular}{|l|l|l|l|l|l|}
\hline Region & \multicolumn{1}{|c|}{ Population } & \multicolumn{1}{|c|}{ Population census size } & \multicolumn{1}{c|}{ Latitude } & Longitude & Altitude (m) \\
\hline \multirow{4}{*}{ UK } & Aberfeldy (AB) & 1,700 & $56^{\circ} 36^{\prime}$ & $3^{\circ} 52^{\prime}$ & 280 \\
\cline { 2 - 6 } & Glen Tilt (GT) & 8,000 & $56^{\circ} 37^{\prime}$ & $4^{\circ} 0^{\prime}$ & 200 \\
\cline { 2 - 6 } & Keltneyburn (KB) & 150 & $56^{\circ} 47^{\prime}$ & $3^{\circ} 50^{\prime}$ & 180 \\
\cline { 2 - 6 } & Loch Ossian (LO) & 1,500 & $56^{\circ} 46^{\prime}$ & $4^{\circ} 36^{\prime}$ & 430 \\
\hline \multirow{3}{*}{ SC } & Karsevagge (KR) & $5,000-10,000$ & $68^{\circ} 26^{\prime}$ & $18^{\circ} 09^{\prime}$ & 600 \\
\cline { 2 - 6 } & Riksgransen (RK) & $2,000-5,000$ & $68^{\circ} 20^{\prime}$ & $18^{\circ} 41^{\prime}$ & 460 \\
\cline { 2 - 6 } & Fiskoy (FS) & $5,000-10,000$ & $68^{\circ} 29^{\prime}$ & $16^{\circ} 04^{\prime}$ & 40 \\
\hline
\end{tabular}

Table 1 Characteristics of the wild populations of small cow-wheat from which seed was collected. 
2007 seed was collected from the UK populations Glen Tilt and Loch Ossian (Table 1), and sown onto tufted vetch (Sarah Dalrymple, pers. comm.). The plants that germinated in 2008 dehisced their seed into the soil. In September 2008 this top layer of soil was collected from each pot and transferred to Royal Botanic Garden Edinburgh (RBGE).

\section{Seed storage}

During fieldwork the seed-bags were stored in a cool, dark, stable environment (for example in an ice box or a fridge) with the tops open. At RBGE, seed-bags were stored in a 'cold room' at $6^{\circ} \mathrm{C}$, in 24-hour darkness, with their tops open. Seed-bags were visually inspected each week for their moisture content and deionised water was dripped into the bags to re-moisten the soil/moss if required. If conditions were too dry the seed became either very hard or waxy and died; likewise, if conditions were too wet the seed turned black and died.

\section{Seed germination and dormancy}

The conditions of the cold room were sufficient to break the seed dormancy and initiate the emergence of the radicle for many seeds. As small cow-wheat is able to remain dormant for two over-wintering seasons before germinating, seeds that do not produce a radicle in the months following collection may simply be in a dormant phase.

\section{Cultivation conditions}

Small cow-wheat was cultivated under two sets of conditions in the RBGE nursery in 2008-2009.

\section{Condition 1: Cultivation of wild collected seed on tufted vetch}

Tufted vetch (Vicia cracca L., Fabaceae) (obtained from Wildflowers UK; see www. wildflowersuk.com) was used as the host species (Dalrymple, 2006). Clean $15 \mathrm{~cm}^{2}$ pots were filled with a potting mixture of 2:1 parts John Innes Number 2 soil and coir. This mixture was designed to retain moisture without becoming waterlogged, and to provide sufficient nutrients for the tufted vetch, but not too many for the small cow-wheat, which grows in acidic, well-draining, nutrient-poor soils in the wild (Dalrymple, 2007). Tufted vetch seeds were scarified with sand in warm soapy water (to make germination more likely) before being sown, two seeds per pot, in early May.

The wild collected small cow-wheat seed was sown in early September. Before sowing, the seeds in each seed-bag were categorised and counted as being either 'mature' or 'immature'. Seeds that were considered 'mature' were a range of sizes, had a smooth, creamy, brownish-white seed-coat, with a white or brown elaiosome (if still attached, Figs 3 \& 6). Seeds that were considered 'immature' were small and had a 'sticky', bright white seed-coat and elaiosome. All the seeds in a seed-bag, including 


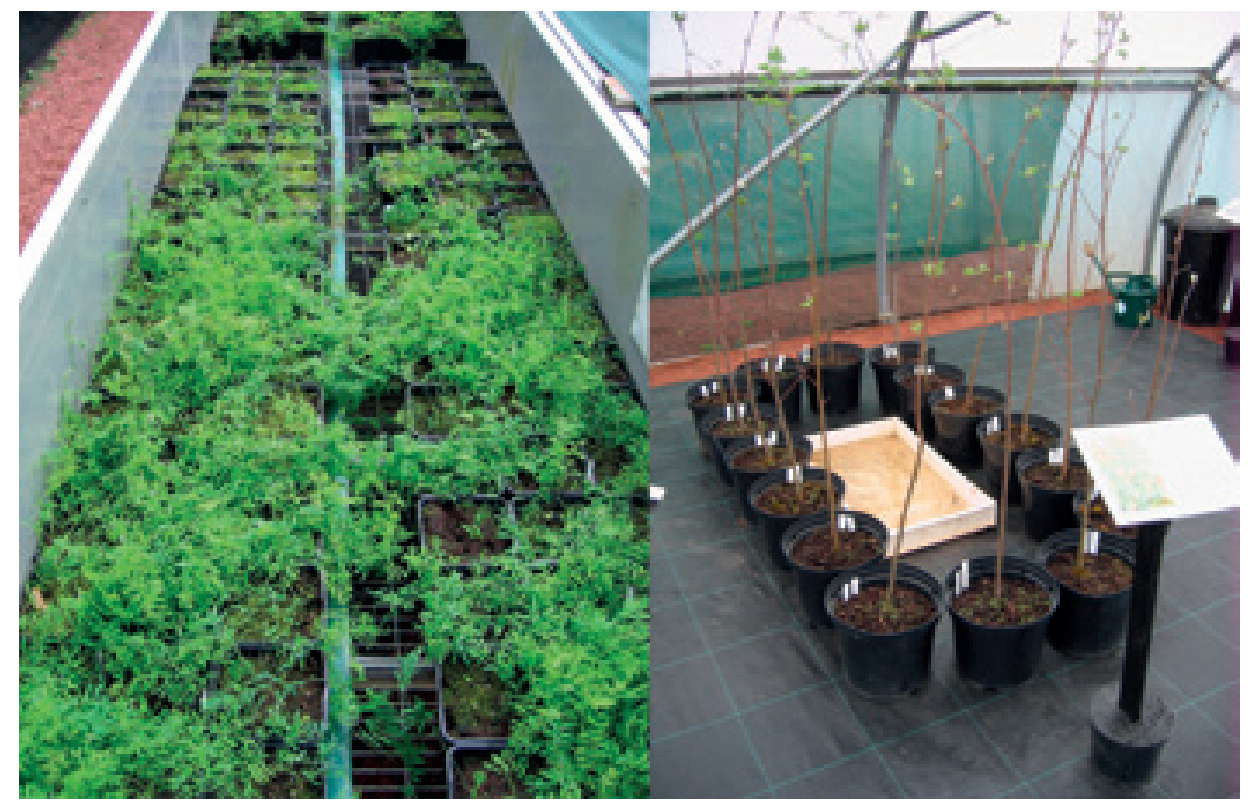

Fig. 4 (a) Cultivation conditions of the wild collected seed sown onto tufted vetch and grown in a cold-frame ('Condition 1'). (b) Cultivation conditions of the botanic garden collected seed sown with emergent radicles onto rowan saplings and grown in a shade tunnel ('Condition 2'). Photos: Rhiannon Crichton.

any 'immature' seeds, were sown into one pot with a tufted vetch plant. The number of seeds sown per pot ranged from one to twenty-eight. 'Immature' seeds were sown because of an uncertainty as to whether they might be capable of germination. Seed was sown into a $1 \mathrm{~cm}$ deep furrow made in the soil surrounding the tufted vetch roots, covered over with soil and watered in.

The pots (one hundred and four in total) were placed in a raised cold frame in the RBGE nursery, three pots deep either side of a water sprinkler that ran through the centre of the cold frame, and covered by a green mesh for shade (Fig. 4a). Over winter the pots were exposed to natural temperatures and precipitation. Over the growing season the pots were watered daily with a sprinkler system.

\section{Condition 2: Cultivation of botanic garden collected seed, whose radicles had already emerged, on rowan}

Rowan (Sorbus aucuparia L., Rosaceae) was used as the host species, based on the observation made by the authors of trees acting as the host species for small cow-wheat in the wild. The rowan saplings were approximately $1.5 \mathrm{~m}$ tall, in 121 pots filled with a potting mixture of 1:1 parts Nursery Stock (Sinclair) and John Innes Number 2 soil.

The seeds collected from the Cruickshank Botanic Garden were kept in the cold room and monitored for radicle emergence. Unlike the trials with seeds grown on tufted vetch, we only planted seeds with emergent radicles. These seeds were sown in October 
into $1 \mathrm{~cm}$ deep furrows surrounding the rowan sapling roots, covered with soil and watered in. A maximum of 20 plants per source population was sown in a pot.

During winter the pots (16 in total) were placed outside in the RBGE nursery. At the beginning of the growing season (April), the pots were moved into a shade tunnel and watered daily with a hose. In order to increase the ambient humidity surrounding the plants, the pots were grouped around an approximately $1 \mathrm{~m} \times 50 \mathrm{~cm}$ container full of water with a small solar-powered pump creating a small water fountain (Fig. 4b). A mist-spraying system would perform this function better.

\section{Germination data collection and analysis}

The number of plants germinated per pot was counted at regular intervals until the middle of May, when no new germination was to be expected. Because the number of seeds sown per pot was variable, average germination rates with upper and lower 95 per cent confidence intervals were obtained by performing a logistic regression within a generalised linear model using R software (R Core Development Team, 2011).

\section{Germination rates obtained}

The average germination rate of the wild collected seeds, using tufted vetch as the host species, was 34 per cent (Table 2). Germination rates by pot (by 'mother' plant) were highly variable, ranging from 0 to 100 per cent (see 'Condition 1' box plot in Fig. 5). Germination rates of seeds from the UK populations ranged from 38 per cent (Glen Tilt, $n=186$; Loch Ossian, $n=229$ ) to 67 per cent (Keltneyburn, $n=12$ ), averaging at 42 per cent. This average value accords well with the reported average germination rate of 40 per cent for wild Scottish populations Aberfeldy and Loch Ossian (Dalrymple, 2007), suggesting that seed dormancy and/or mortality was no higher in the cultivation environment than in wild sites.

The germination rates of the Scandinavian populations ranged from 10 per cent (Riksgransen, $n=242$ ) to 59 per cent (Fiskoy, $n=71$ ), averaging at 21 per cent, half that of the UK populations (Table 2). The low germination rates of Scandinavian populations Riksgransen (10 per cent) and Karsevagge (22 per cent) is likely to be due to two factors. First, these populations are located at altitude, in continental conditions within the Arctic Circle (Table 1). Thus the seeds may not have experienced sufficiently cold temperatures in the RBGE cold room and nursery to break their dormancy. Second, these two populations contained a greater proportion of immature seeds (at the time of collecting) than other populations ( 33 per cent and 45 per cent respectively). These seeds may not have been capable of germinating and have therefore artificially reduced the overall germination rates.

The average germination rate of the botanic garden collected seed, using rowan as the host species, was 75 per cent (Table 3 ). Seeds from Loch Ossian had a greater germination rate than seeds from Glen Tilt, at 81 per cent and 69 per cent respectively (see 


\begin{tabular}{|c|c|c|c|c|c|c|c|}
\hline 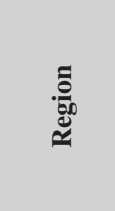 & 总 & 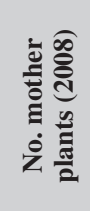 & 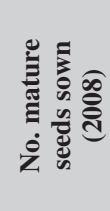 & 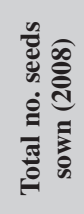 & 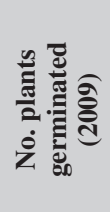 & 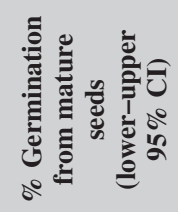 & 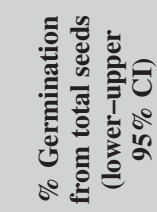 \\
\hline \multirow[t]{4}{*}{ UK } & Aberfeldy & 19 & 152 & 177 & 78 & $51(36-67)$ & $44(30-58)$ \\
\hline & Glen Tilt & 20 & 153 & 186 & 70 & $46(30-61)$ & $38(25-51)$ \\
\hline & Keltneyburn & 5 & 12 & 12 & 8 & $67(15-100)$ & $67(17-100)$ \\
\hline & Loch Ossian & 20 & 209 & 229 & 86 & $41(28-54)$ & $38(26-49)$ \\
\hline UK total & 4 & 64 & 526 & 604 & 242 & $48(30-65)$ & $42(26-58)$ \\
\hline \multirow[t]{3}{*}{$\mathrm{SC}$} & Karsevagge & 16 & 133 & 241 & 53 & $40(24-56)$ & $22(12-32)$ \\
\hline & Riksgransen & 19 & 162 & 242 & 23 & $14(4-25)$ & $10(3-16)$ \\
\hline & Fiskoy & 5 & 55 & 71 & 42 & 76 (55-98) & $59(38-81)$ \\
\hline SC total & 3 & 40 & 350 & 554 & 118 & $32(18-47)$ & $21(11-31)$ \\
\hline Total & 7 & 104 & 876 & 1,158 & 360 & $42(34-50)$ & $34(27-41)$ \\
\hline
\end{tabular}

Table 2 Germination rates of small cow-wheat grown using tufted vetch as the host with wild collected seed.
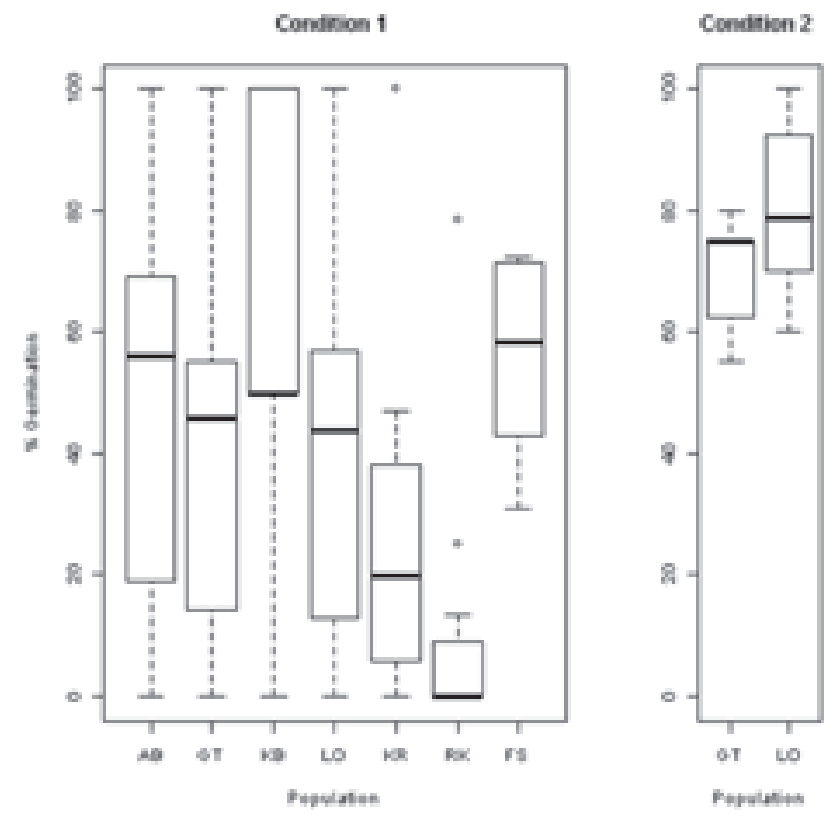

Fig. 5 Box-and-whisker plot showing the percentage of seed that germinated per pot, by population, for both of the cultivation conditions. Each box represents the spread of 50 per cent of the data points, with the black line in the middle representing the median data point. The dashed lines coming out of the box and ending as a flat line represent the spread of the maximum and minimum 25 per cent of data points. Open circles represent outlier data points. Drawn by Rhiannon Crichton. 
'Condition 2' box plot in Fig. 5), and these rates are almost double those achieved by seeds from the same populations when sown without radicles. These high germination rates are likely to be due to the seeds being sown when active, with radicles already produced (and therefore no dormant or immature seeds were sown, as was the case with the seeds sown onto the tufted vetch). Additionally, as the seeds were sourced from a relatively benign cultivation environment, maternal allocation of resources to the seeds may have been greater than in wild populations (Roach \& Wulff, 1987) and this may have enhanced the germination rates.

\begin{tabular}{|l|l|l|l|}
\hline \multicolumn{1}{|c|}{ Population } & \multicolumn{1}{|c|}{$\begin{array}{c}\text { Total no. seeds } \\
\text { sown (2008) }\end{array}$} & \multicolumn{1}{c|}{$\begin{array}{c}\text { No. plants germinated } \\
\mathbf{( 2 0 0 9 )}\end{array}$} & $\begin{array}{c}\text { \% Germination } \\
\text { (lower-upper 95\% CI) }\end{array}$ \\
\hline Glen Tilt & 140 & 97 & $69(59-79)$ \\
\hline Loch Ossian & 148 & 120 & $81(73-89)$ \\
\hline Total & 288 & 217 & $75(71-80)$ \\
\hline
\end{tabular}

Table 3 Germination rates of small cow-wheat grown using rowan as the host and seeds with radicles already emerged.

\section{Observations on subsequent growth}

Plant viability was maintained through the growing season, resulting in large healthy plants that produced seed. Mortality was sporadically observed throughout the course of the growing season, caused by: (1) non-attachment to the host plant, resulting in small, weak and desiccated plants; (2) herbivory of the main stem (including the growing tip) at an early stage in the plant life cycle; (3) the main stem being broken off when the plant was large, through becoming tangled with the tufted vetch tendrils. To remedy these causes of plant mortality, frequent pest control by manually removing any slugs and snails, and cutting the tufted vetch back to below the height of the small cow-wheat plants, can be undertaken.

\section{CONCLUSIONS}

The overall success of the cultivation experiments attest to the suitability of the horticultural protocols that were developed during the course of this research. Seed viability was maintained through the stages of collection, storage during transportation, long-term storage in the cold room (where germination of the radicle was often initiated) and in over-wintering conditions once sown into a pot with a host species. Furthermore, plant viability was maintained throughout the growing season. These horticultural protocols can be used to facilitate further research and conservation activities for small cow-wheat.

These horticultural protocols can be used to facilitate further research and conservation activities for small cow-wheat. It may be prudent to collect seed from a number 
of the small, most-at-risk, wild populations and sow them into cultivation conditions in the RBGE nursery to create a permanent ex situ conservation collection. Seed produced by an ex situ collection can be sown into suitable habitat near to the source population (local expansion), used to establish new populations (translocation, Dalrymple \& Broome 2010) and can be used to maintain the ex situ collection.

The key messages we draw from our observations of cultivating small cow-wheat are:

- Seed should be collected and stored in cold, moist, breathable conditions.

- Seed can remain viable in these conditions for three months, and can potentially remain in these conditions for longer.

- Seed can be cultivated with a variety of hosts.

- Preferentially sowing seeds that have undergone the first germination by producing a radicle leads to higher establishment success. These seeds will die if they do not attach to a host before depleting their own limited resources.

- Seeds that do not produce a radicle may simply be dormant. These seeds can be sown into cultivation conditions alongside active seeds, or stored in the cold room (though the maintenance of seed viability beyond three months of cold-room storage has not been tested).

- Cultivation conditions must meet both the over-wintering requirements of the seed and the growing season requirements of the plant:

- Over-wintering: seeds break their dormancy through prolonged exposure to cold temperatures, including temperatures below freezing.

- Growing season: plants require cool, humid, shaded environments with moist but free-draining soils.

- Small cow-wheat is able to set seed without the need for cross-pollination.

\section{ACKNOWLEDGEMENTS}

We wish to thank all land managers and Scottish Natural Heritage for permission to collect seed; all RBGE nursery staff, especially Pete Brownless and Ross Irvine, for providing space, materials and knowledge, and for watering the plants; Tom Christian for providing the rowan saplings; Heather McHaffie and Natacha Frachon for creating the ex situ collections at Dawyck Botanic Garden; Chantel Davies Sealy for discussions on statistics; and Markus Ruhsam, Sarah Woodin, Alex Twyford, Alistair Jump and Andy Taylor for helpful comments on a draft manuscript. Rhiannon Crichton was supported by a National Environment Research Council PhD studentship and Scottish Natural Heritage grant. 


\section{REFERENCES}

CHEFFINGS, C. \& FARRELL, L. (2005). The Vascular Plant Red Data List for Great Britain. JNCC, Peterborough.

CRICHTON, R.J., SQUIRRELL, J., WOODIN, S.J., DALRYMPLE, S.E. \& HOLLINGSWORTH, P.M. (2012). Isolation of microsatellite primers for Melampyrum sylvaticum (Orobanchaceae), an endangered plant in the United Kingdom. American Journal of Botany, 99(11), in press.

DALRYMPLE, S.E. (2006). Rarity and conservation of Melampyrum sylvaticum. PhD thesis, University of Aberdeen.

DALRYMPLE, S.E. (2007). Biological flora of the British Isles: Melampyrum sylvaticum L. no 246. Journal of Ecology, 95, 583-597.

DALRYMPLE, S.E. \& BROOME, A. (2010). The importance of donor population identity and habitat type when creating new populations of small cow-wheat Melampyrum sylvaticum from seed in Perthshire, Scotland. Conservation Evidence, 7, 1-8.

GLOBAL STRATEGY FOR PLANT CONSERVATION (2002). Published by the Secretariat of the Convention on Biological Diversity, Montreal, Canada, \& Botanic Gardens Conservation International, Kew, UK.

MASSELINK, A.K. (1980). Germination and seed population dynamics in Melampyrum pratense L. Acta Botanica Neerlandica, 29, 451-468.

MOLAU, U. (1993). Relationships between flowering phenology and life history strategies in tundra plants. Arctic and Alpine Research, 25, 391-402.

MUSSELMAN, L.C. \& PRESS, M.C. (1995). Introduction to parastic plants. In: PRESS, M.C. \& GRAVES, J.D. (eds). Parasitic Flowering Plants. Chapman and Hall, London.

PRESS, M.C., GRAVES, J.D. \& STEWART, G.R. (1988). Transpiration and carbon acquisition in root hemiparasitic angiosperms. Journal of Experimental Botany, 39, 1,009-1,014.

R CORE DEVELOPMENT TEAM (2011). R: A language and environment for statistical computing. R Foundation for Statistical Computing, Vienna, Austria. Available online: http:// www.r-project.org/foundation/ (accessed 20 August 2012).

RICH, T.C.G., FITZGERALD, R. \& SYDES, C. (1998). Distribution and ecology of small cowwheat (Melampyrum sylvaticum L., Scrophulariaceae) in the British Isles. Botanical Journal of Scotland, 50, 29-46.

RUMSEY, F.J. (1994). Melampyrum sylvaticum L. Scarce Plants in Britain (eds STEWART, A., PEARMAN, D.A. \& PRESTON, C.D.), JNCC, Peterborough.

SOÓ, R.D. \& WEBB, D.A. (1972). Melampyrum L., In: TUTIN, T.G., HEYWOOD, V.H., BURGES, N.A., MOORE, D.M., VALENTINE, D.H. \& WALTERS, S.M. (eds), Flora Europaea, vol. 3 pp. 253-257. Cambridge University Press, Cambridge.

TENNANT, D. (2008). Melampyrum sylvaticum in England. Watsonia, 27, 23-36.

TĚŠITEL, J., MALINOVA, T., ŠTECH, M. \& HERBSTOVA, M. (2009). Variation in the Melampyrum sylvaticum group in the Carpathian and Hercynian region: two lineages with different evolutionary histories. Preslia, 81: 1-22.

TĚŠITEL, J., PLAVCOVÁ, L. \& CAMERON, D.D. (2010a). Interactions between hemiparasitic 
plants and their hosts: the importance of organic carbon transfer. Plant Signaling \& Behaviour, 5, 1,072-1,076.

TĚŠITEL, J., RíHA, P., SVOBODOVÁ, Š., MALINOVÁ, T. \& ŠTECH, M. (2010b). Phylogeny, life history evolution and biogeography of the Rhinanthoid Orobanchaceae. Folia Geobotanica, 45, 347-367.

UK BIODIVERSITY GROUP (1999). I. Tranche 2 Action Plans - Volume III: Plants and Fungi. JNCC, Peterborough.

WEISS, F.E. (1908). The dispersal of fruits and seeds by ants. New Phytologist, 7, 23-28. 
sibbaldia10.indd 70 21/12/2012 09:20 